\title{
Development of donepezil-induced hypokalemia following treatment of cognitive impairment
}

\author{
Dongryul Kim ${ }^{1}$, Hye Eun Yoon ${ }^{1}$, Hoon Suk Park ${ }^{2}$, Seok Joon Shin ${ }^{1}$, Bum Soon Choi ${ }^{2}$, Byung Soo Kim², \\ Tae Hyun Ban ${ }^{2}$ \\ ${ }^{1}$ Division of Nephrology, Department of Internal Medicine, Incheon St. Mary's Hospital, The Catholic University of Korea, Seoul, Korea \\ ${ }^{2}$ Division of Nephrology, Department of Internal Medicine, Eunpyeong St. Mary's Hospital, The Catholic University of Korea, Seoul, Korea
}

Received: April 11, 2020

Revised: May 7, 2020

Accepted: May 14, 2020

Corresponding author:

Tae Hyun Ban

Division of Nephrology, Department of Internal Medicine, Eunpyeong St. Mary's Hospital, The Catholic

University of Korea, 1021 Tongil-ro,

Eunpyeong-gu, Seoul 03312, Korea

Tel: +82-2-2030-4356

Fax: +82-2-2030-4641

E-mail: deux0123@catholic.ac.kr
Donepezil is a cholinesterase inhibitor used extensively to treat Alzheimer disease. The increased cholinergic activity is associated with adverse effects, therefore gastrointestinal symptoms, including nausea, vomiting, and diarrhea, are common. Hypokalemia is a rare adverse event that occurs in less than $1 \%$ of donepezil-treated patients. Although hypokalemia of mild and moderate grade does not present serious signs and symptoms, severe hypokalemia often results in prolonged hospitalization and mortality. Herein, we report a case of hypokalemia developed after the initiation of donepezil therapy for cognitive impairment.

Keywords: Alzheimer disease; Cognitive dysfunction; Donepezil; Hypokalemia

\section{Introduction}

Hypokalemia is a common electrolyte disturbance in clinical practice. The major causes of hypokalemia include gastrointestinal loss and medications such as diuretics [1,2]. Most cases are asymptomatic and mild, but some patients develop severe hypokalemia resulting in arrhythmias and patient death. About $20 \%$ of inpatients experience hypokalemia during hospitalization [3], and among these cases, severe hypokalemia was sometimes associated with prolonged hospitalization and increased mortality [4].

Donepezil is the second approved acetylcholinesterase inhibitor for the treatment of mild to moderate Alzheimer disease by the United States Food and Drug Administration (FDA), extensively used worldwide [5]. As donepezil is generally tolerated, most adverse events are gastrointestinal symptoms, including vomiting and diarrhea [6]. However, rare adverse events such as lupus, psycho- sis, and arrhythmia have been reported in a few patients $[7,8]$. According to the FDA, hypokalemia is a rare adverse event that occurs in less than $1 \%$ of donepezil-treated patients $[9,10]$.

Notably, hypokalemia exhibits non-specific symptoms such as general weakness, fatigue, dyspepsia, myalgia, tingling sensation, muscle cramps, and spasms; hence, it can be difficult to diagnose without laboratory investigations. Therefore, clinicians sometimes fail to recognize the signs and symptoms of hypokalemia. Accordingly, a rare case of hypokalemia induced by medication is significant. Herein, we report a case of hypokalemia developed after initiating donepezil as a treatment for cognitive impairment.

\section{Case}

The study was approved by the Institutional Review Board of the Catholic University of Korea (IRB No: PC20ZASI0046) with

Copyright (C) 2021 Yeungnam University College of Medicine

This is an Open Access article distributed under the terms of the Creative Commons Attribution Non-Commercial License (http://creativecommons.org/licenses/by-nc/4.0/) which permits unrestricted non-commercial use, distribution, and reproduction in any medium, provided the original work is properly cited. 
waiver of informed consent.

An 87-year-old man visited the outpatient clinic owing to poor oral intake. According to his medical history, he had undergone surgery for benign prostatic hyperplasia 6 years ago and had discontinued the medication for benign prostatic hyperplasia 4 months before hospitalization. Recently, he was diagnosed with cognitive dysfunction based on a mini-mental status examination score of 22, and a global deterioration scale of 3 . And was started on appropriate medication. At the time of admission, he was prescribed choline alfoscerate $400 \mathrm{mg}$ twice daily and donepezil $5 \mathrm{mg}$ for the control of Alzheimer disease.

A review of systems did not reveal abnormal findings. His vital signs were as follows: blood pressure (BP), $180 / 70 \mathrm{mmHg}$; pulse rate, 72 beats/min; respiratory rate, 20 breaths/min; body temperate, $36.7^{\circ} \mathrm{C}$. To determine the cause of poor oral intake, routine investigations were performed, including complete blood count, blood chemistry, urine analysis, electrocardiogram, and chest $\mathrm{X}$-ray. The presence of subtle pneumonia on the chest X-ray and hypokalemia (serum potassium $2.6 \mathrm{mmol} / \mathrm{L}$ ) was detected. Initial serum inflammatory markers showed the following results: plasma leukocyte count, $7,500 / \mathrm{mm}^{3}$; serum c-reactive protein, $0.74 \mathrm{mg} /$ $\mathrm{dL}$ (range, $0.01-0.5 \mathrm{mg} / \mathrm{dL}$ ). Except for potassium, blood chemistry revealed the following: serum albumin, $4.0 \mathrm{~g} / \mathrm{dL}$ (range, 3.5$5.2 \mathrm{~g} / \mathrm{dL}$ ); blood urea nitrogen, $10.9 \mathrm{mg} / \mathrm{dL}$; serum creatinine, $0.72 \mathrm{mg} / \mathrm{dL}$ (range, $0.61-1.20 \mathrm{mg} / \mathrm{dL}$ ); serum sodium, 140 $\mathrm{mmol} / \mathrm{L}$; serum chloride, $91 \mathrm{mmol} / \mathrm{L}$; serum magnesium, 2.4 $\mathrm{mg} / \mathrm{dL}$; serum osmolality, $290 \mathrm{mOsm} / \mathrm{kg}$. Urinalysis and urine sediment examination presented the following: urine $\mathrm{pH}, 7.5$; urine specific gravity, 1.011; urine white blood cells, $0-2 /$ high power field; urine red blood cells, $0-2 /$ high power field. Blood gas analysis revealed compensated metabolic alkalosis as follows: arterial blood $\mathrm{pH}$, 7.52; arterial blood $\mathrm{pCO}_{2}, 46.6 \mathrm{mmHg}$; arterial blood $\mathrm{pO}_{2}, 73.7 \mathrm{mmHg}$; arterial blood $\mathrm{HCO}_{3}^{-}, 36.8 \mathrm{mmol} / \mathrm{L}$. Chest X-ray and inflammatory markers suggested that the pneumonia was not severe. Therefore, hypokalemia could be the cause of underlying poor oral intake.

The patient was admitted to treat pneumonia and hypokalemia. For pneumonia treatment, he received ceftriaxone and clarithromycin as antibiotic agents. To determine the cause of hypokalemia, further investigations were performed. No clues indicating hypokalemia were detected in the medical history and review of systems. Next, his renal potassium excretion was measured to determine the potassium/creatinine ratio, fractional excretion of potassium, and transtubular potassium gradient (TTKG), using blood chemistry and spot urine chemistry. The results of spot urine chemistry were as follows: urea nitrogen, $392.8 \mathrm{mg} / \mathrm{dL}$; creatinine, $90.8 \mathrm{mg} / \mathrm{dL}$; total protein, $29.9 \mathrm{mg} / \mathrm{dL}$; sodium, $35 \mathrm{mEq} / \mathrm{L}$; potassium, $29.2 \mathrm{mEq} / \mathrm{L}$; chloride, $45 \mathrm{mEq} / \mathrm{L}$; osmolality, 309 $\mathrm{mOsm} / \mathrm{kg}$. Additionally, the following values were determined and suggested renal potassium wasting: urine potassium/creatinine ratio, $32.2 \mathrm{mEq} / \mathrm{g}$; fractional excretion of potassium, $8.9 \%$; TTKG, 10.5. Those findings suggested renal potassium wasting. Next, computed tomography demonstrated no abnormalities in the bilateral adrenal glands and both kidneys (Fig. 1). A hormone study was conducted to evaluate the cause of high BP. The thyroid function test was in the normal range. The adrenocorticotropic hormone (ACTH) level was $36.02 \mathrm{pg} / \mathrm{mL}$ (range, $10.0-60.0 \mathrm{pg} /$ $\mathrm{mL}$ ) and the cortisol level was $10.51 \mu \mathrm{g} / \mathrm{dL}$ (range, 9.41-26.06 $\mu \mathrm{g} /$
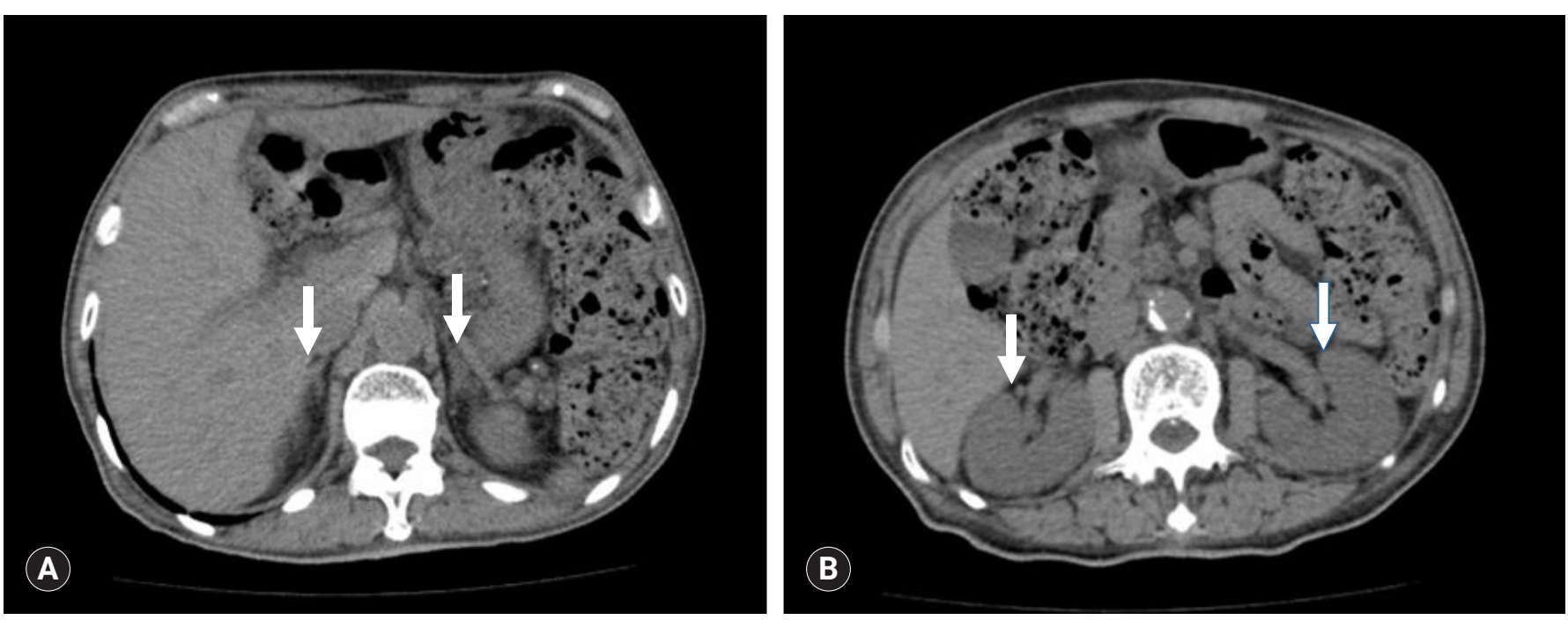

Fig. 1. Abdominal computed tomography scan. (A) Both adrenal glands (arrows) show no abnormalities. (B) Both kidneys (arrows) show no abnormal findings. 
$\mathrm{dL}$ ), which were within the normal range, revealing no mineral corticoid excess. Plasma renin activity was determined as $0.19 \mathrm{ng} /$ $\mathrm{mL} / \mathrm{hr}$ (range, $0.3-2.9 \mathrm{ng} / \mathrm{mL} / \mathrm{hr}$ ), aldosterone concentration was $14.93 \mathrm{pg} / \mathrm{mL}$ (range, $29.9-158.8 \mathrm{pg} / \mathrm{mL}$ ), and the aldosterone/renin ratio was 7.86, indicating hyporeninemic hypoaldosteronism. However, unlike Liddle syndrome, the serum sodium level was normal at $140 \mathrm{mmol} / \mathrm{L}$. The serum magnesium level was normal at $2.4 \mathrm{mg} / \mathrm{dL}$, which was far from that observed in Gitelman syndrome. Hence, no obvious cause of hypokalemia was determined.

During investigations analyzing the possible cause of hypokalemia, he underwent potassium supplementation using intravenous and oral formulations. Until the fourth day of hospitalization, his serum potassium level demonstrated difficulty increasing beyond $3.0 \mathrm{mmol} / \mathrm{L}$ despite sufficient potassium administration (Fig. 2). As the hypokalemia was poorly corrected, clinicians suspected other causes of hypokalemia. A thorough review of the therapeutic agents prescribed for cognitive dysfunction was conducted. On examining possible adverse effects, we identified evidence suggesting that donepezil causes hypokalemia as a rare adverse event $[9,10]$. Therefore, donepezil was immediately discontinued. Thereafter, his potassium demand, supplemented intravenously, gradually de- creased and was modified to oral potassium agents. On the third day after donepezil cessation, his serum potassium level recovered to $3.5 \mathrm{mmol} / \mathrm{L}$ under oral potassium supplementation of $32 \mathrm{mEq} /$ day (Fig. 2). During hypokalemia evaluation and correction, pneumonia was properly controlled. Finally, he was able to maintain serum potassium of $3.3 \mathrm{mmol} / \mathrm{L}$ under oral potassium supplementation of $32 \mathrm{mEq} /$ day and was discharged on the ninth day of hospitalization. At the time of discharge, the results of blood chemistry and spot urine chemistry were as follows: serum creatinine, 0.73 $\mathrm{mg} / \mathrm{dL}$; serum potassium, $3.5 \mathrm{mmol} / \mathrm{L}$; serum magnesium, 2.3 $\mathrm{mg} / \mathrm{dL}$; serum osmolality, $295 \mathrm{mOsm} / \mathrm{kg}$; urine creatinine, 120.6 $\mathrm{mg} / \mathrm{dL}$; potassium, $46.7 \mathrm{mEq} / \mathrm{L}$; osmolality, $330 \mathrm{mOsm} / \mathrm{kg}$. Additionally, the following values were determined: urine potassium/ creatinine ratio, $38.7 \mathrm{mEq} / \mathrm{g}$; fractional excretion of potassium, 8.1\%; TTKG, 11.9.

Conversely, in the past, he had presented a systolic BP of less than $130 \mathrm{mmHg}$ and diastolic $\mathrm{BP}$ of $80 \mathrm{mmHg}$ during several visits to the outpatient clinic, with no history of medication-related hypertension. However, for 24 hours after hospitalization, BP was continuously confirmed as $160 / 90 \mathrm{mmHg}$ or more, including a maximum of $185 / 105 \mathrm{mmHg}$, and amlodipine $5 \mathrm{mg}$ was initiated.

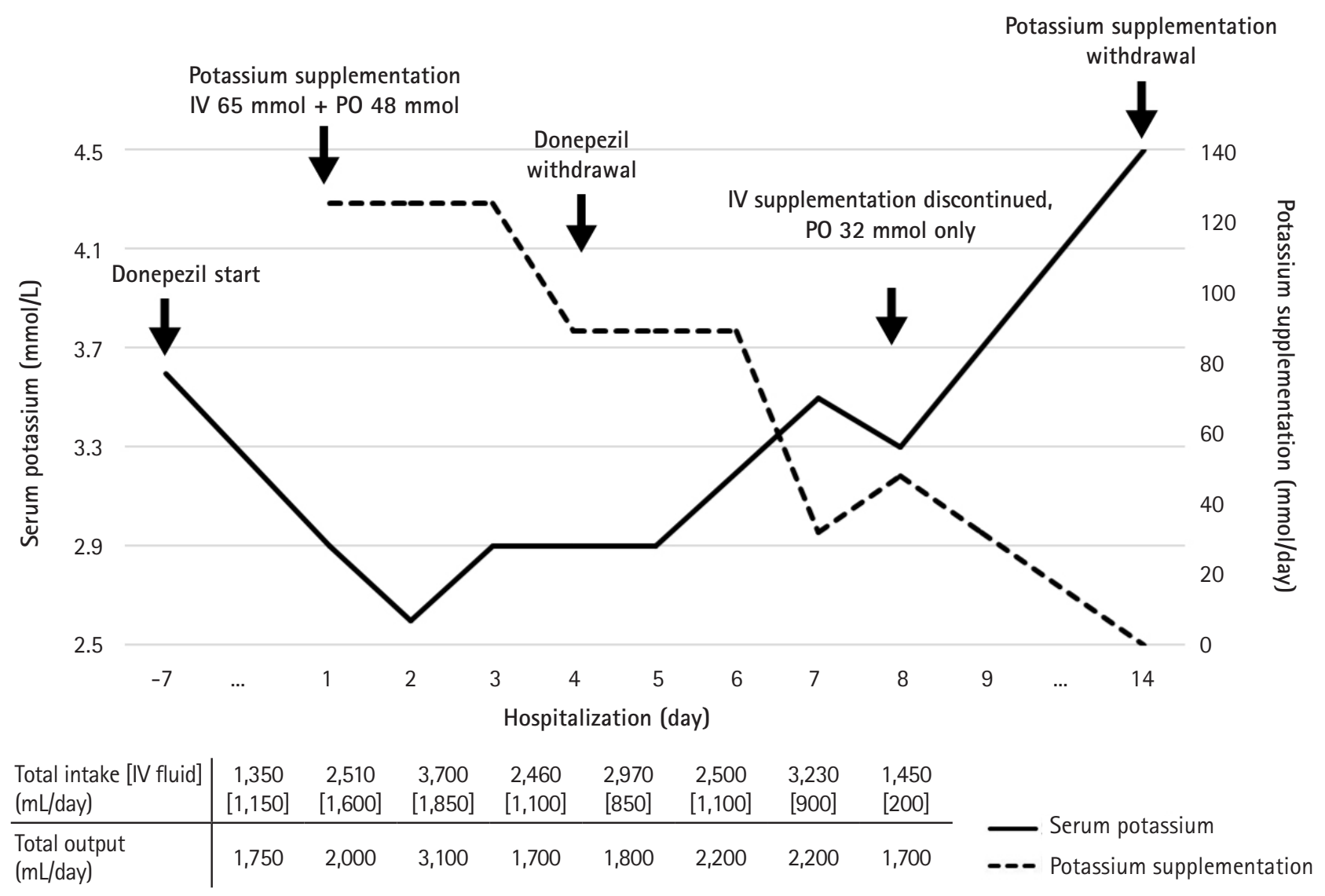

Fig. 2. Summary of serum potassium level, potassium supplementation, total intake, and total output per day. IV, intravenous; PO, per oral. 
As BP measurements were above $140 / 90 \mathrm{mmHg}$ on average after the addition of amlodipine $5 \mathrm{mg}$, the patient was additionally prescribed olmesartan $20 \mathrm{mg}$ on the fifth day of hospitalization. Finally, in the outpatient clinic follow-ups, serum potassium was measured as $4.5 \mathrm{mmol} / \mathrm{L}$, and oral potassium agents were withheld.

\section{Discussion}

This case report presents the rare development of hypokalemia with donepezil, an agent used to treat cognitive dysfunction. The most common cause of hypokalemia is gastrointestinal losses, followed by medications such as diuretics $[1,2]$. Additionally, various conditions lead to hypokalemia. For example, the following factors result in the development of renal potassium wasting: malignant hypertension, renal artery stenosis, renin-secreting tumors that can increase renin, adrenal hyperplasia, Cushing syndrome, medication including diuretics, magnesium deficiency, Gitelman syndrome, and chronic metabolic acidosis [3]. However, it is difficult to implicate donepezil, used for cognitive dysfunction therapy, as a causative agent. If this patient had multiple prescriptions, donepezil was probably not considered a major cause of hypokalemia.

Donepezil is a cholinesterase inhibitor, mainly prescribed for Alzheimer disease. By inhibiting acetylcholinesterase, donepezil improves behavioral and cognitive symptoms, including confusion, aggression, and psychosis [11,12]. In several studies, donepezil has demonstrated improved cognitive functions in patients with dementia, but it had some adverse effects [13]. The adverse effects were associated with increased cholinergic activity, and the gastrointestinal system was mainly affected. Therefore, nausea, vomiting, and diarrhea were the most common symptoms, as well as insomnia, abnormal dreams, hepatotoxicity, and cardiovascular adverse events [14]. Hypokalemia was one of the rare adverse effects.

The mechanism by which donepezil causes hypokalemia remains unclear. In this case, based on TTKG, potassium excretion continued under donepezil therapy. Therefore, we hypothesized the mechanism by which donepezil caused renal potassium wasting. This finding may be due to the action of donepezil on the ion channels in the renal tubule or Henle's loop. Donepezil could potentially inhibit the $\mathrm{Na}^{+}-\mathrm{K}^{+}-2 \mathrm{Cl}^{-}$cotransporter in the thick ascending limb of Henle's loop, suppressing potassium reabsorption. Additionally, it could be postulated that donepezil stimulates the renal outer medullary potassium channel to excrete potassium. As another hypothesis, donepezil could affect the sodium channel epithelium in the principal cell of the collecting tubule. Thereafter, potassium appeared to be secreted into the lumen to maintain electrolyte balance. Although the mechanism by which donepezil induces hypokalemia remains unclear, we anticipated that renal potassium wasting would recover after its withdrawal. Unfortunately, the follow-up study did not achieve demonstrate an improvement in renal potassium wasting. Based on previous reports, we speculated the possible reasons by which recovery from renal potassium wasting may vary from 2 days to 3 months $[15,16]$. Therefore, the patient may require further time for recovery. Nonetheless, this case was significant as it confirmed the progression of hypokalemia recovery, necessitating a decrease in the daily amount of potassium supplementation after the withdrawal of donepezil.

A limitation of this case report is that we have not done additional research regarding how donepezil affects the renal ion channels. Further case reports and research would assist in determining the mechanism by which donepezil causes renal potassium wasting. Although donepezil demonstrates rare serious adverse events, symptoms during early therapy require a differential diagnosis for hypokalemia.

\section{Acknowledgments}

\section{Conflicts of interest}

No potential conflict of interest relevant to this article was reported.

\section{Author contributions}

Conceptualization: all authors; Data curation: DK, THB, HSP; Formal analysis: DK, THB, HEY, BSC, BSK; Investigation: DK, THB, HEY, HSP; Methodology, Project administration: THB; Supervision: THB, BSC, BSK; Validation: THB, SJS, BSC, BSK; Writing-original draft: DK; Writing-review \& editing: DK, THB, HEY, HSP, SJS.

\section{ORCID}

Dongryul Kim, https://orcid.org/0000-0002-1322-1887

Hye Eun Yoon, https://orcid.org/0000-0002-6347-7282

Hoon Suk Park, https://orcid.org/0000-0002-1102-5460

SeokJoon Shin, https://orcid.org/0000-0001-7642-2849

Bum Soon Choi, https://orcid.org/0000-0002-1412-9951

Tae Hyun Ban, https://orcid.org/0000-0002-2884-4948

\section{References}

1. Crop MJ, Hoorn EJ, Lindemans J, Zietse R. Hypokalaemia and subsequent hyperkalaemia in hospitalized patients. Nephrol Dial Transplant 2007;22:3471-7.

2. Widodo D, Setiawan B, Chen K, Nainggolan L, Santoso WD. The prevalence of hypokalemia in hospitalized patients with infectious diseases problem at Cipto Mangunkusumo Hospital, 
Jakarta. Acta Med Indones 2006;38:202-5.

3. Unwin RJ, Luft FC, Shirley DG. Pathophysiology and management of hypokalemia: a clinical perspective. Nat Rev Nephrol 2011;7:75-84.

4. Paltiel O, Salakhov E, Ronen I, Berg D, Israeli A. Management of severe hypokalemia in hospitalized patients: a study of quality of care based on computerized databases. Arch Intern Med 2001;161:1089-95.

5. Li HC, Luo KX, Wang JS, Wang QX. Extrapyramidal side effect of donepezil hydrochloride in an elderly patient: a case report. Medicine (Baltimore) 2020;99:e19443.

6. Arai H, Hashimoto N, Sumitomo K, Takase T, Ishii M. Disease state changes and safety of long-term donepezil hydrochloride administration in patients with Alzheimer's disease: Japan-Great Outcome of Long-term trial with Donepezil (J-GOLD). Psychogeriatrics 2018;18:402-11.

7. Cubeddu LX. Drug-induced inhibition and trafficking disruption of ion channels: pathogenesis of QT abnormalities and drug-induced fatal arrhythmias. Curr Cardiol Rev 2016;12: 141-54.

8. Manzo C, Putignano S. Drug-induced lupus erythematosus associated with donepezil: a case report. Age Ageing 2015;44: 1062-3.

9. US Food and Drug Administration (FDA). Highlights of prescribing information: Aricept [Internet]. Silver Spring (MD):
FDA; 2012 [cited 2020 Feb 20]. https://www.accessdata.fda. gov/drugsatfda_docs/label/2012/020690s035,021720s008, 022568s005lbl.pdf.

10. eHealthMe. Will you have hypokalemia with Donepezil? (a study of FDA data) [Internet]. eHealthMe; 2020 [cited 2020 Feb 20]. https://www.ehealthme.com/ds/donepezil/hypokalemia/.

11. Li XL, Hu N, Tan MS, Yu JT, Tan L. Behavioral and psychological symptoms in Alzheimer's disease. Biomed Res Int 2014; 2014:927804.

12. Seltzer B. Donepezil: a review. Expert Opin Drug Metab Toxicol 2005;1:527-36.

13. Dunn NR, Pearce GL, Shakir SA. Adverse effects associated with the use of donepezil in general practice in England. J Psychopharmacol 2000;14:406-8.

14. Jackson S, Ham RJ, Wilkinson D. The safety and tolerability of donepezil in patients with Alzheimer's disease. Br J Clin Pharmacol 2004;58(Suppl 1):1-8.

15. Tabish M, Mahendran M, Ray A, Vikram NK. Colistin-induced acquired Bartter-like syndrome: an unusual cause of meltdown. BMJ Case Rep 2020;13:e232630.

16. Min HK, Kim EO, Lee SJ, Chang YK, Suh KS, Yang CW, et al. Rifampin-associated tubulointersititial nephritis and Fanconi syndrome presenting as hypokalemic paralysis. BMC Nephrol 2013;14:13. 